\title{
Maternal and Fetal outcome in Third Trimesters Bleeding
}

\author{
Dr. Anamika Purohit ${ }^{1}$, Dr. Ranjana Desai ${ }^{2}$, Dr. B.S. Jodha ${ }^{3}$, \\ Dr. Babulal Garg ${ }^{4}$ \\ ${ }^{1 .}$ Final year P.G.student, Department of Obstetrics and Gynaecology, Dr S.N. Medical College, Jodhpur, India \\ 2. Professor and Unit Head, Department of Obstetrics and Gynaecology, Dr S.N. Medical College, Jodhpur, \\ India \\ ${ }^{3}$ Associate Professor, Department of Obstetrics and Gynaecology, Dr S.N. Medical College, Jodhpur, India \\ 4. Final year P.G.student, Department of Obstetrics and Gynaecology, Dr S.N. Medical College, Jodhpur, India
}

\begin{abstract}
:
Objective - To evaluate clinical profile, maternal and foetal outcome in third trimester bleeding with the aim to reduce maternal and foetal morbidity and mortality in future. Methods - It is prospective and descriptive study from $1^{\text {st }}$ February to 30 November 2012. Study included all cases of Third trimester bleeding (134 cases) in which 76 Live Birth, 58 Perinatal Mortality and 2 Maternal Mortality. Clinical features, complications and maternal mortality were evaluated. Data was analysed as percentage of total cases studied. Results -Incidence of third trimester bleeding was 1 in 144 deliveries, being higher with increased age and parity. Most common risk factor is previous caesarean section for placenta previa and hypertension for abruption placentae. Maternal mortality was $1.49 \%$ and perinatal mortality was $43.28 \%$.Conclusion -Abruptio placenta and placenta previa remain important causes of perinatal mortality and maternal mortality in third trimester bleeding.
\end{abstract}

Keywords: Abruption placenta, antepartum haemorrhage, perinatal mortality, placenta previa,third trimester bleeding.

\section{Introduction}

Bleeding in pregnancy exclusive in third trimester and its effect on maternal and fetal outcome is one rarely studied. Third trimester bleeding is when a women experiences vaginal bleeding during last part of pregnancy i.e. from 28 weeks to delivery. It is one of grave obstetrical emergency and fear to pregnant women, challenge to obstetrician and is a concern for patients and her doctor.

\section{Methods And Study Design}

1. This study was carried out in the Department of Obstetrics \& Gynaecology, Umaid Hospital attached to Dr. S.N. Medical College, Jodhpur after approval from ethical committee. It is prospective and descriptive study.

2. The cases included all pregnant women booked or unbooked coming with a complaint of amenorrhoea more than 28 weeks and bleeding per vagina. The total days of study were 303 days from 1 February to 30 November 2012.

3. During study period total number of deliveries conducted was 19361. Of this 255 women had antepartum haemorrhage of which 134 had third trimester bleeding.

\section{Observations}

Table No. 1 Age Wise Distribution of Cases of Third Trimester Bleeding

\begin{tabular}{|c|c|c|c|c|c|c|c|c|}
\hline Age & \multirow{2}{*}{ Total } & \multirow{2}{*}{$*$} & \multicolumn{2}{|c|}{ Placenta Previa } & \multicolumn{2}{c|}{ Abruptio Placenta } & \multicolumn{2}{c|}{ Unclassified } \\
\cline { 4 - 9 } & & & No. & $(\%)$ & No. & $(\%)$ & No. & $(\%)$ \\
\hline 15-20 Yrs & 11 & 8.02 & 2 & 4.15 & 9 & 11.25 & - & - \\
\hline $21-25$ Yrs & 55 & 4.04 & 21 & 39.62 & 33 & 41.25 & 1 & 100 \\
\hline $26-30$ Yrs & 38 & 28.35 & 19 & 35.84 & 19 & 23.75 & - & - \\
\hline $31-35$ Yrs & 20 & 14.22 & 10 & 18.86 & 10 & 12.5 & - & - \\
\hline $36-40$ Yrs & 10 & 7.46 & 1 & 1.88 & 9 & 11.25 & - & - \\
\hline TOTAL & 134 & & 53 & - & 80 & - & 1 & - \\
\hline
\end{tabular}


Table No. 2 Distribution of Cases According to Gravida in Third Trimster Bleeding

\begin{tabular}{|l|c|c|c|c|c|c|}
\hline \multirow{2}{*}{ APH } & \multicolumn{2}{|c|}{ PrimiGravida } & \multicolumn{2}{c|}{ Multi Gravida (2 to 4) } & \multicolumn{2}{c|}{ Grand Multi Gravida (5 or More ) } \\
\cline { 2 - 7 } & No. & $(\%)$ & No. & $(\%)$ & No. & $(\%)$ \\
\hline Placenta Previa & 3 & 5.66 & 39 & 73.58 & 11 & 20.75 \\
\hline Abruptio Placentae & 20 & 25 & 43 & 53.75 & 17 & 32.07 \\
\hline Unclassified & 1 & 100 & - & - & - & - \\
\hline TOTAL & 24 & 17.91 & 82 & 61.19 & 28 & 22.58 \\
\hline
\end{tabular}

Table No. 3 Risk Factor Associated With Placenta Previa / Abruptio Placenta

\begin{tabular}{|l|c|c|c|c|}
\hline \multirow{2}{*}{ Various Risk Factor } & \multicolumn{2}{|c|}{ PLACENTA PREVIA } & \multicolumn{2}{|c|}{ ABRUPTION PLACENTA } \\
\cline { 2 - 5 } & No. & $(\%)$ & 5 & 13.15 \\
\hline Previous Caesarean Section & 14 & 40 & 24 & 63.15 \\
\hline PIH in present Pregnancy & 7 & 16 & 2 & 7 \\
\hline History of abortions & 4 & 16 & 3.26 & 18.42 \\
\hline Recurrence Case & 4 & & 38 \\
\hline Total & 25 & & \\
\hline
\end{tabular}

Table No. 4 Analysis of Management of Cases of Third trimester Bleeding

\begin{tabular}{|c|c|c|c|c|c|c|c|c|}
\hline \multirow[t]{2}{*}{$\begin{array}{l}\text { Mode of } \\
\text { Delivery }\end{array}$} & \multicolumn{2}{|c|}{$\begin{array}{l}\text { Percentage of Mode of } \\
\text { Delivery }\end{array}$} & \multicolumn{2}{|c|}{ Placenta Previa } & \multicolumn{2}{|c|}{ Abruptio Placenta } & \multicolumn{2}{|c|}{ Unclassified } \\
\hline & No. & $(\%)$ & No. & $(\%)$ & No. & $(\%)$ & No. & $(\%)$ \\
\hline $\begin{array}{l}\text { Normal } \\
\text { Delivery }\end{array}$ & 21 & 15.67 & 4 & 7.54 & 17 & 21.25 & - & - \\
\hline $\begin{array}{l}\text { Caesarean } \\
\text { Section }\end{array}$ & 105 & 78.35 & 44 & 83.01 & 60 & 75.00 & 1 & 100 \\
\hline $\begin{array}{l}\text { Caesarean } \\
\text { Hysterectomy }\end{array}$ & 8 & 5.97 & 5 & 9.43 & 3 & 3.75 & - & - \\
\hline
\end{tabular}

Table No. 5 Foetal Out Come in Patients with Placenta Previa

\begin{tabular}{|l|c|c|c|c|}
\hline Foetal Outcome & Full term & Pre Term & Total & $(\%)$ \\
\hline Alive & 23 & 13 & 36 & 67 \\
\hline Neonatal Death & 2 & 6 & 1 & 8 \\
\hline Still Birth & 1 & 0 & 3 & 32.07 \\
\hline IUD & 5 & 3 & \\
\hline
\end{tabular}

Table No. 6 Foetal Out Come in Patients with Abruptio Placenta

\begin{tabular}{|l|c|c|c|c|}
\hline Foetal Outcome & Full Term & Pre Term & Total No. & $(\%)$ \\
\hline Alive & 31 & 8 & 39 & 48.75 \\
\hline Neonatal Death & 6 & 4 & 10 & 12.50 \\
\hline Still Birth & 3 & - & 3 & 3.75 \\
\hline IUD & 17 & 11 & 28 & 35 \\
\hline
\end{tabular}

\section{Discussion}

Antepartum haemorrhage still ranks one of the gravest obstetric emergency. Even with the best obstetric care due to dramatic suddenness, a pregnant woman can become exsanguinated due to bleeding in third trimester of pregnancy. It is one of the major causes of maternal and foetal mortality throughout the world, occurring in 3 to 4 percent of all pregnancies. All vaginal bleeding in later month is alarming and want immediate evaluation. Second trimester bleeding though very common is seldom discussed due to low foetal salvage rate (25.32). Thus the present study was exclusively focused on third trimester bleeding.

1. Total 19361 patients delivered during this period. The percentage of antepartum haemorrhage (255 cases) in total deliveries was 1.36 percent in present study. Third trimester bleeding constituted 134 cases $(0.692 \%$ of total deliveries and $52.54 \%$ of total antepartum haemorrhage cases).

2. Total cases of third trimester bleeding were 134, out of which 53 cases $(39.55 \%)$ were due to placenta previa, 80 cases $(59.70 \%)$ of abruptio placenta and in 1 case was unclassified type. Thus accidental haemorrhage was commonest cause of third trimester bleeding followed by placenta previa(Table-2).

3. It was observed that out of total 134 cases only 19 were booked and 115 were unbooked, reporting in emergency due to vaginal bleeding. This shows lack of education, unawareness and ignorance regarding antenatal care.

4. Maximum number of cases were between age group 20-30 years in both group i.e. $93(69.40 \%)$ cases out of 134 because of highest fertility is in this age group(Table-1).

5. The majority $(61.19 \%)$ of third trimester bleeding patients were multigravida (Table- 2$)$.

6. Of the total 134 cases of third trimester bleeding, 52 cases $(38.80 \%)$ presented with various risk factors. Previous caesarean section was most common risk factor for placenta previa and hypertension for abruption placentae(Table-3). 
Risk of placenta previa is highest in the pregnancy immediately following caesarean section. Failure of appropriate lower segment devolvement, because of scar tissue could be cause and raw area favourable for implantation. Incidence of placenta previa increases in a linear way with increasing number of previous caesarean section.

Hypertensive disorder during pregnancy has accounted for a relatively high incidence of cases of abruptio placentae. Presence of hypertension can double the foetal mortality from abruption. The greatest determinant of abruption risk is an abruption in a prior pregnancy. This was quantified by Ananth and Colleagues in tometa-analysis. The risk increased 15 to 20 fold in subsequent pregnancies when an earlier pregnancy was complicated by abruption. In present study $16 \%$ of pregnancies again complicated by abruptio placenta which co-relates with the same. Hence, again it is stress on regular antenatal care and BP monitoring of all pregnant patients, attending antenatal clinic.

7. Of the total 134 patients of third trimester bleeding, 34 cases $(25.37 \%)$ had severe anemia $(\mathrm{Hb}<7 \mathrm{gms}$ $\%$ ) and only 25 cases $(18.65 \%)$ had normal hemoglobin level. This was the limitation in the study because of more number of unbooked patients. In some patients visual estimation of blood loss did not co-relate with the anaemic status, hence it was presumed that those women were already anaemic and slight bleeding further worsened the hemoglobin status.

8. Seventy one cases $(52.58 \%)$ presented with preterm pregnancy and bleeding per vagina. The incidence of prematurity was higher in placenta previa contributing $69.72 \%$ as compare to, abruption where it was $42.5 \%$ (Table-5,6). The patients had to be delivered due to life threatening haemorrhage.

9. In majority of third trimester bleeding cases (107cases i.e. $79.85 \%)$ foetal presentation was vertex and 27 cases $(21.15 \%)$ having malpresentation. Placenta previa had more malpresentation $(28.30 \%)$ in comparison to abruptio placenta in which $15 \%$ had malpresentation. It is due to the fact that in placenta previa bulk of placenta in lower segment preventing engagement of foetal head.

10. There was high percentage (105cases i.e $78.35 \%)$ of Caesarean section in third trimester bleeding; vaginal delivery was only in 21 cases $(15.67 \%)$. Eight cases $(5.92 \%)$ had Caesarean hysterectomy because of atonic PPH and placenta accrete (Table-4).Majority of the operations were done as a desperate attempt to save the mother and foetus. Hence the higher incidence of caesarean section in present series.

11. The perinatal loss was higher in patients who delivered vaginally as compared to those delivered by Caesarean Section. In present series 49 cases delivered by caesarean section and the perinatal loss of 13 cases $(26.54 \%)$ as compared with vaginal delivery in which perinatal loss was $100 \%$. It is found to reason that if the low lying placenta is the most likely source of bleeding in pregnancy, there may exist some compromise with uteroplacental perfusion and those pregnancies may not tolerate the stress of labour. Also saying that vaginal delivery can lead to $100 \%$ perinatal death, would be incorrect. A large multicentric analysis is required to see the outcome in vaginal birth.

12. In the placenta previa $67.92 \%$ of the female had live baby at the time of discharge. The perinatal mortality was high accounting of $32.07 \%$; of them there was 1 still birth and 8 neonatal deaths. The high incidence of perinatal mortality is due to the fact that 8 cases were having absent foetal heart sound at the time of admission, 6 cases required an ICU admission due prematurity babies. Two term baby were lost in neonatal period of the patients who were unbooked referred from periphery with pre-existing anemia, cause of death in these neonatal were septicemia. The most common cause of neonatal death was prematurity.

13 .The signs and symptoms with abruptio placentae can vary considerably, the typical initial presentation in $16 \%$ cases $(19.04 \%)$ there was bleeding per vagina without pain, 62 cases $(76.19 \%)$ bleeding with pain abdomen and 4 cases (4.765) also had added headache and vertigo, eclampsia was associated with $4.76 \%$ of cases of third trimester bleeding.

14. The toxaemia was present in 24 patients i.e. $30 \%$ cases. Hypertension was seen in $30 \%$ of patients with abruptio placenta which include 4 cases of eclampsia.

15. There were 59 patients $(73.75 \%)$ of revealed type, 7 patients of concealed type $(8.75 \%)$ and $17.5 \%$ have mixed type. The percentage of revealed haemorrhage was high

16. The total number of third trimester bleeding 134 patients, 80 pregnancy of abruptio placenta, $38 \%$ were fatal to fetus with $3(3.75 \%)$ still birth, $17(35 \%)$ IUD, there were 6 neonatal death contributing to increased perinatal mortality of $51.25 \%$ as shows in table no.6

17. The PPH was the most common complication in $35.07 \%$ of cases necessitating hysterectomy in 6 cases. It occurred in $14 \%$ of placenta previa, $20.14 \%$ in abruptio placentae.

Atonic PPH is common in abruptio because of damage to myometrium, atony and coagulopathy, fibrin and fibrin degradation factors inhibit myometrical contractility. The risk should be anticipated in all patients with abruption. It can be prevented or treated.

Maternal mortality in present series was $1.49 \%$. Maternal death in ante partum haemorrhage Quoted by $\operatorname{Dutta} \mathrm{s}^{[1]}(2011)<1$ to as high as $5 \%$ and according to william (2007) it is $1-3 \%$ of total delivery, which is nearly similar. The re-laparotomy in caesarean section- The rate of re-exploration after caesarean was $0.2 \%$ as 
reported by Ishai Levin et al 2012. In their series placental abruption was important risk factor where as in present series re-laparotomy was done in caesarean section due to placenta previa. The case of central placenta previa with previous caesarean section taken for emergency caesarean due to 1 bout of bleeding during expectant treatment, after 3-4 hours patient had developed atonic PPH, in spite of all preventive measure uterus was relaxed and flabby, so patient had taken for re-laparotomy and total abdomen hysterectomy done.

18. The near miss morbidity in Third trimester bleeding was found in 14 cases i.e. $5.49 \%$.

Near miss is defined as any patient who is pregnant or recently delivered (within 6 weeks after delivery) in whom immediate survival is threatened and who survive by chance or because of hospital care she received. It was calculated according to Gellers criteria ${ }^{[2]}$. Four patients had geller score 10 and remaining nine patients had Geller score 8.

\section{Conclusion}

Present study was done at Umaid Hospital, Jodhpur in which total number of delivery 19631during period 1 Feb to 30 November 2012. Out of total delivery 254 cases $(1.36 \%)$ were antepartum Haemorrhage of which 134 cases $(52.14 \%)$ had Third Trimester Bleeding.

1) Antenatal care was provided only in 19cases (14.17\%), 63 cases (47.01\%) were referred out of 134.

2) Parity and age: Frequency of placenta previa and abruption placenta increases remarkably with increasing parity and age. The ratio of primigravida to multigravida was found to be 1:4 in cases of placenta previa and 1:2 in cases of abruption placenta.

Hence age with high parity should be considered as independent risk factor for third trimester bleeding.

3) Risk Factor: In patients with placenta previa most common risk factor was previous caesarean section seen in $40 \%$ of cases followed by pervious abortion in $16 \%$ of cases. While PIH was the risk factor contributing $40.54 \%$ of third trimester bleeding in abruption placenta.

4) $52.58 \%$ of patients had gestational age less than 36 week with malpresentation in $26.6 \%$ cases of pl.previa and $15 \%$ cases of abruption.

5) Mode of delivery: In placenta previa was by caesarean section in 113 cases $(92.46 \%)$ in which 5 case $(5.97 \%)$ required caesarean hysterectomy. Vaginal delivery was conducted in 4 cases $(7.54 \%)$. Perinatal mortality in operative and vaginal delivery was $73.46 \%$ and $100 \%$ receptively. In abruption placenta 63 cases $(78.75 \%)$ caesarean section in which 3 cases $(3.75)$ caesarean hysterectomy done and 17 cases $(21.25 \%)$ were normal delivered. Thus concluding that third trimester bleeding increases the risk of operative delivery.

6) There were 2 maternal deaths in the present series- 1 in placenta previa due to PPH caused by placenta accereta and 1 in abruption placenta with eclampsia.

7) In present series the perinatal mortality was $32.07 \%$ in placenta previa and $51.25 \%$ in abruption.

8) Complications: Postpartum haemorrhage was the major complication in patients with placenta previa and accidental haemorrhage. Primary PPH was found in $14.92 \%$ and $20.14 \%$ of patient with placenta previa and abruption placenta respectively. Eight cases (5.97\%) were in shock on admission and $8(5.97 \%)$ patients went in DIC. Couvelaire uterus was seen in 10 cases $(7.46 \%)$ of patients.

Nevertheless awareness through antenatal classes, better socioeconomic status, efficient referrals system, good neonatal intensive care facilities is obviously required for the foetal perinatal and maternal outcome in developing country.

\section{Acknowledgements}

We sincerely acknowledge Dr. Bharat Paliwal, Assistant Professor (Anesthesia), Dr.S.N.Medical College, Jodhpur for providing support and assistance in preparing this paper.

\section{References}

[1]. Hiralal Konar ,D.C.Dutta's,Textbook of obstetrics,7th edition,chapter18(antepartum haemorrhage),(Kolkata, New central book agency,2011)pages 241-259

[2]. Susan Birk," Gellers Score gauges maternal care quality”, Obs/Gyn News/10 Oct.2009. 